\title{
Anonymous Feedback Using Digital Walls: A Case Study
}

\author{
Besma Allagui \\ Rabdan Academy Abu Dhabi, UAE \\ besma.allagui@yahoo.fr
}

\begin{abstract}
A common problem faced by many language teachers is students' fear from speaking in front of the whole class and making mistakes. Research showed that reticence to participate in class may influence students' language learning who may miss important opportunities for correction. This paper reports on students' reactions to the use of digital walls to provide anonymous oral feedback and to maximize students' participation. The students engaged in answering three-minute instructor-posed questions on their mobile devices using an application called Quick fire as found on www.spiral.ac. The anonymous answers were displayed instantaneously on the smartboard which allowed the instructor to provide the students with realtime feedback. The students answered 14 questions after eight weeks of instruction. At the end of the project, the students were invited to focus group discussions in order to delve into their opinions about using digital walls for providing feedback and encouraging class participation. Qualitative analysis of the students' comments indicated that they had a generally positive experience and that anonymous posting can foster students' engagement.
\end{abstract}

Keywords: Digital Wall, Feedback, Participation

\section{Introduction}

It is often frustrating when you ask a question in class and you do not get answers form all students or you get answers from the same students willing to participate. Students' participation is increasingly viewed as a sign of successful instruction. It allows the teacher to check students' understanding of the lesson and engagement with the material presented. It is also important for learners. It can foster a positive learning environment in which students feel confident. Students' participation has become the main goal of most teachers especially in technology-rich classrooms where students have ample opportunities for interaction and collaboration. While much has been written on ways to encourage participation using a variety of digital tools, little research has been conducted to examine students' beliefs about those tools. This paper reports on the finding of a study examining students' opinion about Quick fire, a free web application that enabled the students to post their answers on the smartboard.

Definition of participation: Participation is often equated with engagement. However, participation is only one part of the broader term engagement. According to Handel man, Briggs, Sullivan \& Towler (2005) student engagement includes four factors: skills, participation/interaction, emotional, and performance. Participation can be written or oral. Often it is used to refer to discussion with the instructor or classmates. But it also means exchanging pieces of writing. As it comes in many forms, participations also has different purposes ranging from checking if the students meet the learning objectives to checking boredom and disinterest in the lesson.

Influences on language learning: Researchers have long been concerned about lack of participation in the classroom. Many studies showed that lack of participation interferes with communication and with critical thinking skills (Davis, 1993; Fassinger, 1995; Weaver and Qi, 2005). A student who is reluctant to participate in class activities misses out important opportunities for practice and feedback (Weaver and Qi, 2005). Some other studies showed that students who participate actively in class have more favorable attitudes towards their instructors than students who do not participate (Crombie et al., 2003; Fassinger, 1995). Consequently, the student is more open to correction. Opponents of this view used it as a justification to include participation in class grading policies. Although some researchers are still in doubt about whether participation should be graded or not, most agree that it is an essential component of any learner-centered approach. The main reasons for reticence to participating in class are fear from error correction and anxiety 
(Horwitz, 2000).The way students ' output is treated plays an important role in their desire to participate. Some error correction techniques may destroy the students' confidence and self-esteem. There is an agreement among researchers that teachers should be careful when correcting students' errors (Ferris, 2007). Various techniques such as focus on form and praise have been advocated.

With the advent of technology, the students are able to participate without fearing criticism or embarrassment. Barnes, Marateo \& Ferris (2007a) provided a list of tools that can be used to enhance students' engagement including blogs, web quests, wikis, interactive games, etc... Writing on digital walls is one of the tools that can foster whole class participation. However, it is surprising that very little research has been conducted worldwide to investigate the benefits from and challenges in writing on digital walls. Working with students who often prefer not to speak even if they know the right answer, the researcher decided to explore ways to overcome challenges in participation by providing anonymous feedback. To meet this goal, the researcher used a free web application called Quick fire. The application allowed the teacher to ask a question and get responses from their students on their own devices; a timer can also be added to add an element of competition. The responses can be viewed on the teacher screen anonymously. By employing Quick fire as a tool to engage students, this case study attempted to show how new evolving tools can be used to create a motivating learning environment. The remainder of this paper is divided as follows: Section one describes the Quick fire application. Section two describes the setting, the participants and the methodology used. Section three presents and discusses the validity of the results. Section four, summarizes the article.

\section{Figure 1: Student view}

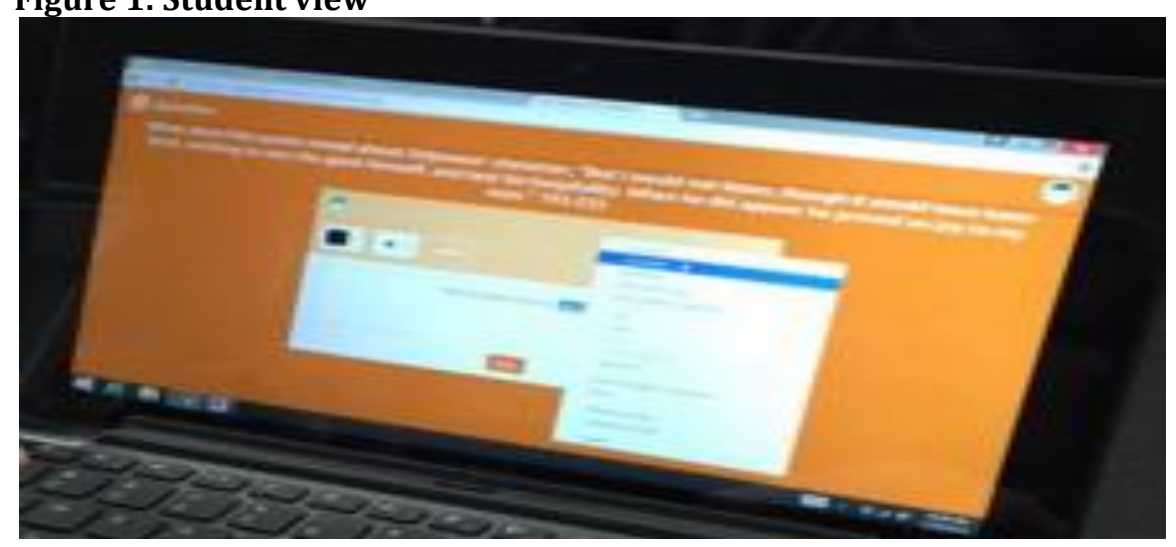

Figure 2: Teacher view

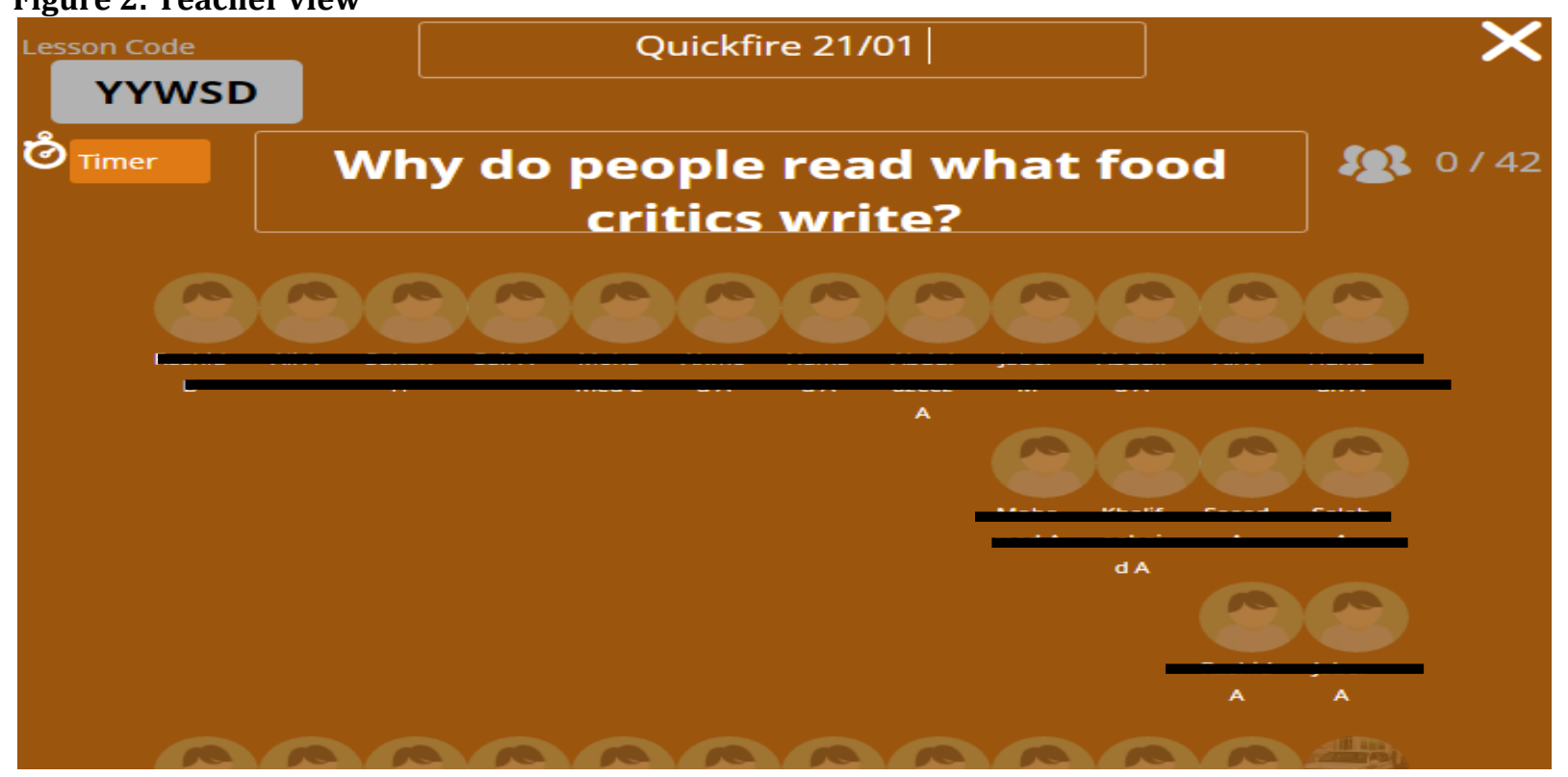


Quick fire - A collaborative tool: Using Quick fire is very simple. First, you have to go to http://spiral.ac/ and select login as teacher. You will be given the option to create an account via email, Google+ or Twitter. Students sign-up is also very simple. They need to go to www.spiral.ac and select student login. They will be required to search for their college and then type their first name, last name and a password. To make it easier for my students, I created an account for each one of them and on the first day of class I provided them with a username and a password. Starting from February, 19th, 2016 the administrators changed the student login so that the students simply type the lesson code every time they use spiral. Figure 1 and figure 2 illustrate the student and the teacher view of the Quick fire element in Spiral

The case study context: Participants for this study were 21 students enrolled in a university preparatory class at a university in Abu Dhabi. Their English skills were lower than average as they were placed in level two based on their scores at IELTS (3.5-4.5). They all had to attend the reading and vocabulary course. The course aims at developing the students' Lexile level and helping them to use the vocabulary in their writing and reading classes. Before the study, the course instructor engaged in reading and vocabulary activities for nine weeks. There were eight reading passages and for every reading the students had to answer four discussion questions. For this project, the students answered 14 questions using the Quick fire application. The students would be allowed to use their mobile devices to answer the questions and post them on the smartboard. After eight weeks of instruction, the students were invited to answer seven interview questions to better understand the effect of the digital tool on their learning.

\section{Methodology}

An action research approach provides some insights into the benefits and challenges of using the Quick fire application in the classroom. This study expected that using Quick fire application would not only provide the instructor with an opportunity to provide anonymous feedback, but also would allow the instructor to create a learning environment that encourages whole-class participation and engagement with the activities. In order to understand better the effect of the Quick fire application on the students' learning outcomes, a qualitative research methodology was adopted. For each reading, the researcher aimed to explore students' behavior as demonstrated in their posts. Interview questions elicited students' perceptions of using Quick fire in the classroom to provide further support to classroom observations. In addition, comparison of the results from the two sources yielded reliable evidence of the particulars of Quick fire use.

\section{Research objectives}

- To incorporate the Quick fire element to foster whole-class participation and to give real-time feedback.

- To investigate students' perceptions of using the Quick fire activities.

Data analysis: To determine the impact of Quick fire on students' performance and participation, students' posts written in the first four weeks were compared to the posts written in the second four weeks. Qualitative findings were triangulated with finding from the teacher's observations. To understand students' opinion about Quick fire, participants' interviews were transcribed and examined for recurring themes. Validity concerns were addressed primarily through the triangulation of data sources.

\section{Findings}

Observation of the students and examination of their posts from the first week till the eighth week showed several changes in students' performance and attitude to the digital tool. These changes are summarized below:

At the beginning of the project, the students provided short answers limiting their posts to a single word or a phrase. Some answers were either yes or no. As their language developed, the students' responses showed more complexity and they could answer in complete sentences. A screenshot as shown in Figure 3 illustrates the progression in students' learning: 


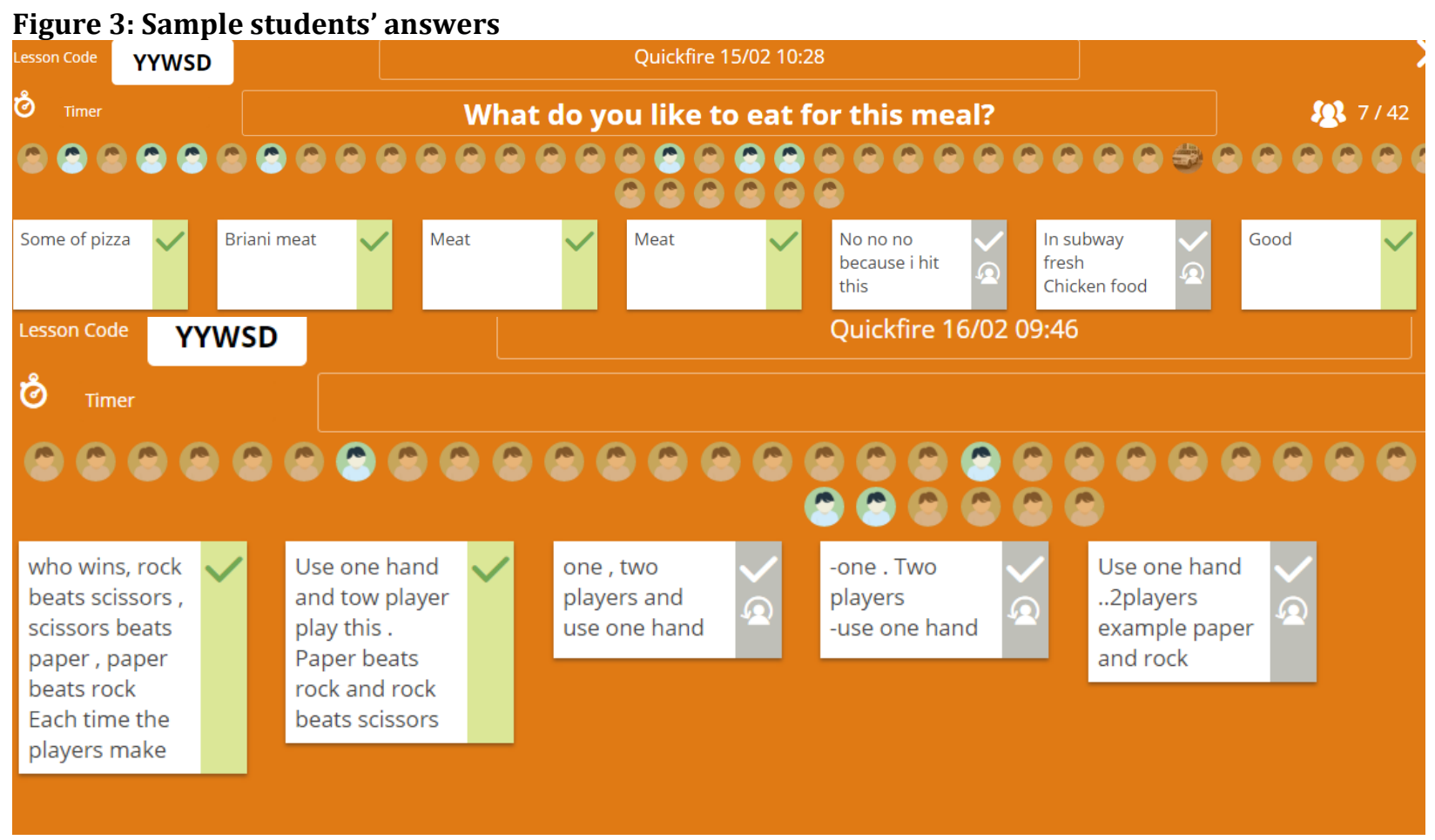

Another important change involved the interval between writing and posting. In week one and two, most of the students would answer immediately after reading the question. However, starting from the third week, most of the students preferred to wait and look at their classmates' responses on the smartboard. They would answer after they compare their answers with their classmates and sometimes could not answer because they run out of time. With regards to anonymity, students seemed to benefit from not seeing their names on the smartboard. They sometimes laughed at a post and started guessing the identity of the author. They also complimented the good answers as the instructor was constantly giving them feedback. The students clearly developed a sense of criticism towards themselves and their classmates. Furthermore, the aspect of anonymity in Quick fire often resulted in lowering the spirit of competitiveness. However, lack of competitiveness did not deter the students from editing their posts. It was clear that they did not want to be regarded as lacking. This might mean that they developed the ability to self-assess their learning.

After eight weeks, participant reported their opinions about the project. The researchers held group interviews with the students and asked them seven open-ended questions. Analysis of students' comments revealed interesting differences between the students in their experience of using the Quick fire application. About half of the students (49\%) reported that they enjoyed the tool. This was not surprising as it was clear from the observation that the students were not so excited about the application. Below is a screenshot that portrays their reactions to spiral:

\section{Figure 4: Students' reactions to the use of Quick fire}

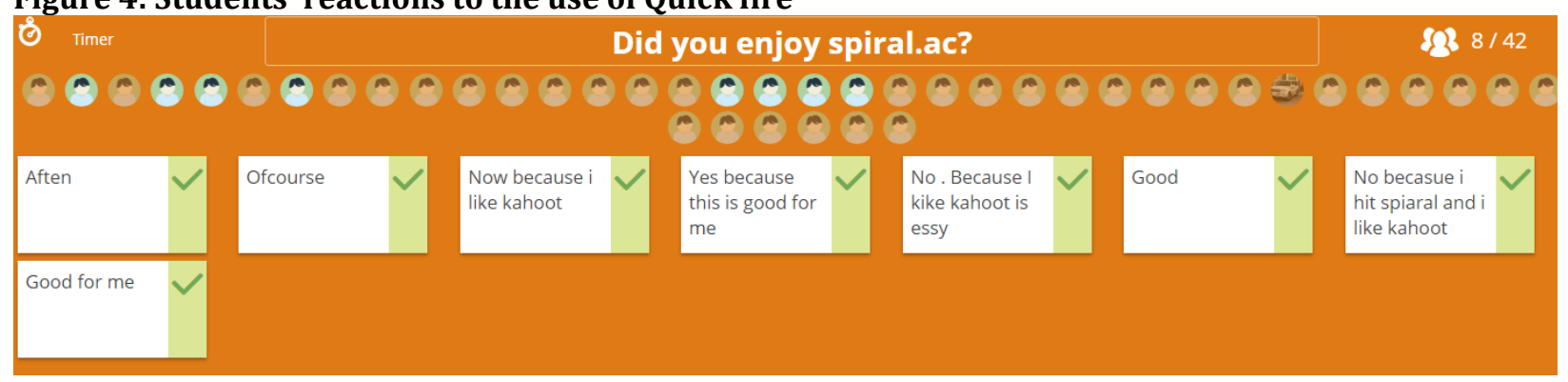


When further questioned about what they enjoyed most when using Quick fire, the students reported various reasons.

Student \# 21. It's interesting because I can see my answer on the smartboard.

Student \# 4. I like using my phone in class.

Student \# 20. I look at my friends answer.

Student \# 1. I can talk with my friend.

The analysis of the open comment questions offered some useful guidelines on the benefits gained from using the Quick fire application and the challenges encountered. The students agreed that although at the beginning the set-up of an account was time consuming, they believed that logging in became much easier as they had to enter the same lesson code after their initial set-up. Five students mentioned having technical difficulties as they were unable to post their responses. Below are some comments:

Student \# 6. The reason why I don't like this app is that I can't post. I press many times but it is not working.

Student \# 14. It did not work on my phone.

Student \# 17. I can't post my writing.

Among the benefits of Quick fire, the students mentioned the ability to receive timely feedback and edit their posts based on clear teacher feedback. They seemed to value revising their posts and felt that they had a growing understanding of what the instructors expected from them. Some comments received from learners in the open comments section are as follow:

Student \# 21. Anonymous posting is a good way to write anything that comes to my mind.

Student \# 4. I look at all those posts and say nobody will say if my post was good or bad.

Student \# 20. When you send me a well-done message I show it to my classmates. And it is nice to see my answer on the wall.

It is interesting that students liked the tool because their identities were hidden. This finding indicates that the Quick fire application lowered students' anxiety. Therefore, it is helping them to be more engaged in the reading and vocabulary class.

The collaborative aspect of the application was also an emerging theme in the students' comments. Many students reported that they enjoyed reading their classmates' answers. Although they did value reading each other's responses, they could not decide if they should copy their classmates' answers or not.

Student \# 12. I don't know if the one who wrote this sentence is a good student or not.

Self-assessment was more important than learning from peers. In fact, there were more positive comments about being able to revise their errors than about the collaborative aspect of the tool. Clearly, the students perceived that feedback from the instructor was more important than feedback from their peers. The results from the open-ended questions supported the results from the observation and examination of students posts. All students seemed to enjoy using Quick fire as a new digital tool. They recognized the benefits and the challenges involved. Although they liked the anonymous aspect of the tool, they were not so influenced by its collaborative aspect.

Discussion and Implications: The results showed that the students had an overall positive experience with the Quick fire element of spiral. While some students reported several challenges involved in using this tool for learning, this finding could be normal as it was a new experience and they needed time to practice using the Quick fire element. Despite those challenges, only two students reported that they did not see the value of using Quick fire in the classroom. The majority of the participants emphasized that the application offered them a number of advantages. First, the students reported that it allowed them to revise their writing and this was a valuable self-assessment tool. Second, many reported that posting their writing anonymously lowered their anxiety and allowed them to be more comfortable in class. These findings are also in line with the literature suggesting that students are reluctant to participate because they do not like to be corrected in front of their peers. Although the Quick fire questions were not graded, from observation, there was a clear improvement in students' writing evidenced by the increase in the length of their posts. The study could be improved by including students' grades and assigning participants to conditions rather than intact classes. 


\section{Conclusion}

Overall, this small-scale study shows some useful findings about the use of digital walls in improving wholeclass participation and in providing timely anonymous feedback. The results suggest that students enjoyed posting their answers on a digital wall and gained insights into their thinking. These preliminary findings highlight aspects that can hinder or help participation. Future studies are warranted to assess students' posts and to understand the relationship between students' posts and their learning.

\section{Appendix A \\ Interview questions:}

- Did you enjoy spiral.ac? What did you enjoy the most about using spiral.ac?

- Has posting your answer on the smartboard helped you understand the lesson better?

- Has posting anonymously helped you write better answers?

- Did you enjoy reading your classmate's answers?

- Were you classmates' answers helpful?

- How easy was it to log in?

- How easy was it to post your answer?

\section{References}

Barnes, K., Marateo, R. \& Ferris, S. P. (2007a). Teaching and Learning with the Net Generation. Innovate Journal of Online Education, 3(4). Retrieved from: http://www.innovateonline.info/pdf/vol3_issue4/Teaching_and_Learning_with_the_Net_ Generation.pdf

Crombie, G., Pyke, S. W., Silverthorn, N., Jones, A. \& Piccinin, S. (2003). Students' perceptions of their classroom participation and instructor as a function of gender and context. The Journal of Higher Education, 74, 51-76.

Davis, B. G. (1993). Tools for Teaching. San Francisco: Jossey-Bass.

Fassinger, P. A. (1995a). Professors' and students' perceptions of why students participate in class. Teaching Sociology, 24, 2533. (ES)

Ferris. (2007). Preparing teachers to respond to student writing. Journal of second language writing, 16, 165193.

Handelsman, M. M., Briggs, W. L., Sullivan, N. \& Towler, A. (2005). A measure of Promoting College Student Course Engagement. The Journal of Educational Research, 98, 184-191.

Horwitz, E. K. (2000). It ain't over 'til it over: on foreign language anxiety first language deficits and confounding of variables.

Roblyer, M. (2003). Integrating Educational Technology into Teaching. (3rd ed.) Upper Saddle River, NJ: Merrill Prentice Hall.

Weaver, R. R. \& Qi, J. (2005). Classroom organization and participation: College students' perceptions. The Journal of Higher Education, 76, 570-601. (ES) 